\title{
A new species of Apteroscirtus Karsch, 1891 (Ensifera, Tettigoniidae, Mecopodinae) from Angola
}

\author{
CLAUDIA HEMP ${ }^{1} \&$ MERCEDES PARÍS ${ }^{2}$ \\ ${ }^{\prime}$ Senckenberg Biodiversity and Climate Research Center, Frankfurt/Main, Germany, University of Bayreuth, Dept. Plant Systematics, \\ Germany. \\ झ"claudia.hemp@uni-bayreuth.de; † https://orcid.org/0000-0001-9170-7113 \\ ${ }^{2}$ Museo Nacional de Ciencias Naturales (CSIC), Colección de Entomología. C/ José Gutiérrez Abascal 2, 28006 Madrid (España). \\ ”=mercedes-paris@mncn.csic.es; @ https://orcid.org/0000-0002-0161-7278
}

\begin{abstract}
A new species of Apteroscirtus is described from Angola, enlarging the known area of distribution of this genus to westsouthern Africa.
\end{abstract}

Key words: Africa, taxonomy, new species

\section{Introduction}

The genus Apteroscirtus contains at present six species with three species confined to the Eastern Arc Mountains of Tanzania, one species from the Ruwenzori Mountains along the Albertine Rift in western Uganda on the border with the Democratic Republic of the Congo, and two species from the Democratic Republic of the Congo and Cameroon. Five of the six species are apterous or only have tiny lobe-shaped remains of former wings (Hemp 2020) while males of A. inalatus (Karsch, 1886) have reduced but otherwise well-developed tegmina and very likely are able to produce songs. As far as information is available Apteroscirtus are inhabitants of the forest floor and are perfectly adapted to the litter layer but can also be found sitting on taller herbs at night. When studying the Orthoptera collection of the Museo Nacional de Ciencias Naturales (MNCN-CSIC) in Madrid (Spain) three specimens collected in northern Angola of a new Apteroscirtus species were found and the new species is described here.

\section{Material and methods}

Measurements. The total body length refers to the body length of the insect from head to the tip of the abdomen including the male subgenital plate in males but without the ovipositor of the female.

Depository. MNCN: Museo National de Ciencias Naturales, Madrid, Spain.

\section{Results}

\section{Apteroscirtus dundoensis n. sp. Hemp, C.}

Holotype male. Angola, Dundo (Lunda); A. De B. Machado B. Machado, February 1948 (MNCN_Ent 305876). Depository: MNCN.

Paratypes: 1 female, same data as holotype, but June 1948 (MNCN_Ent 305877). 1 female, Angola, Rio Tchinguvos Lunda, Machado, July 1948 (MNCN_Ent 305878). Depository: MNCN. 


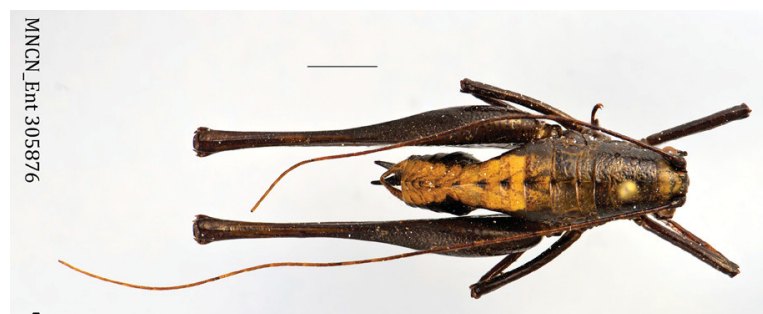

A

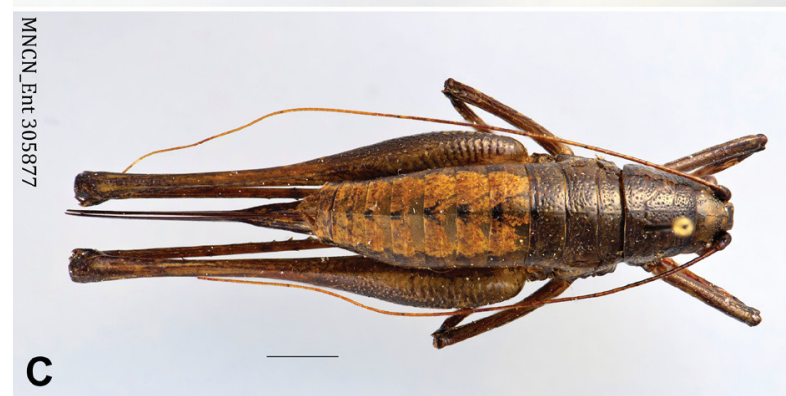

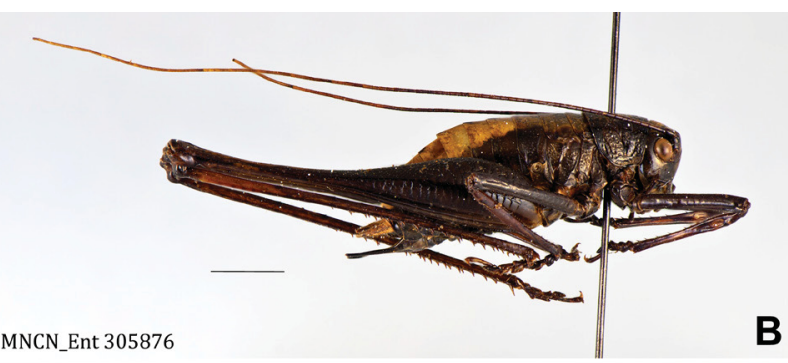

MNCN Ent 305877

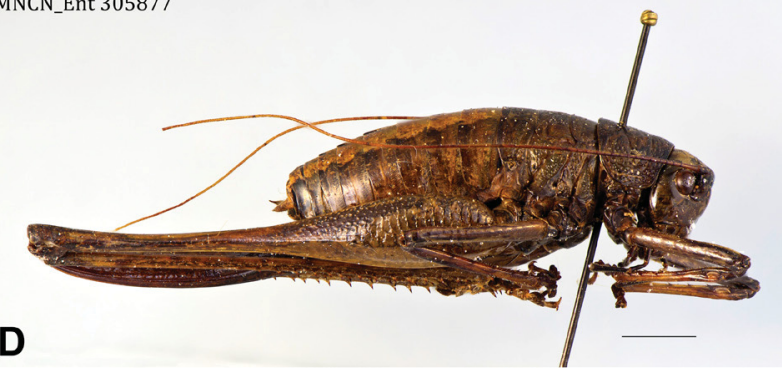

FIGURE 1. Habitus of Apteroscirtus dundoensis n. sp. A. Male (MNCN_Ent 305876), dorsal and B. lateral C. Female (MNCN_ Ent 305877), dorsal and D. lateral. Scale bar $5 \mathrm{~mm}$.
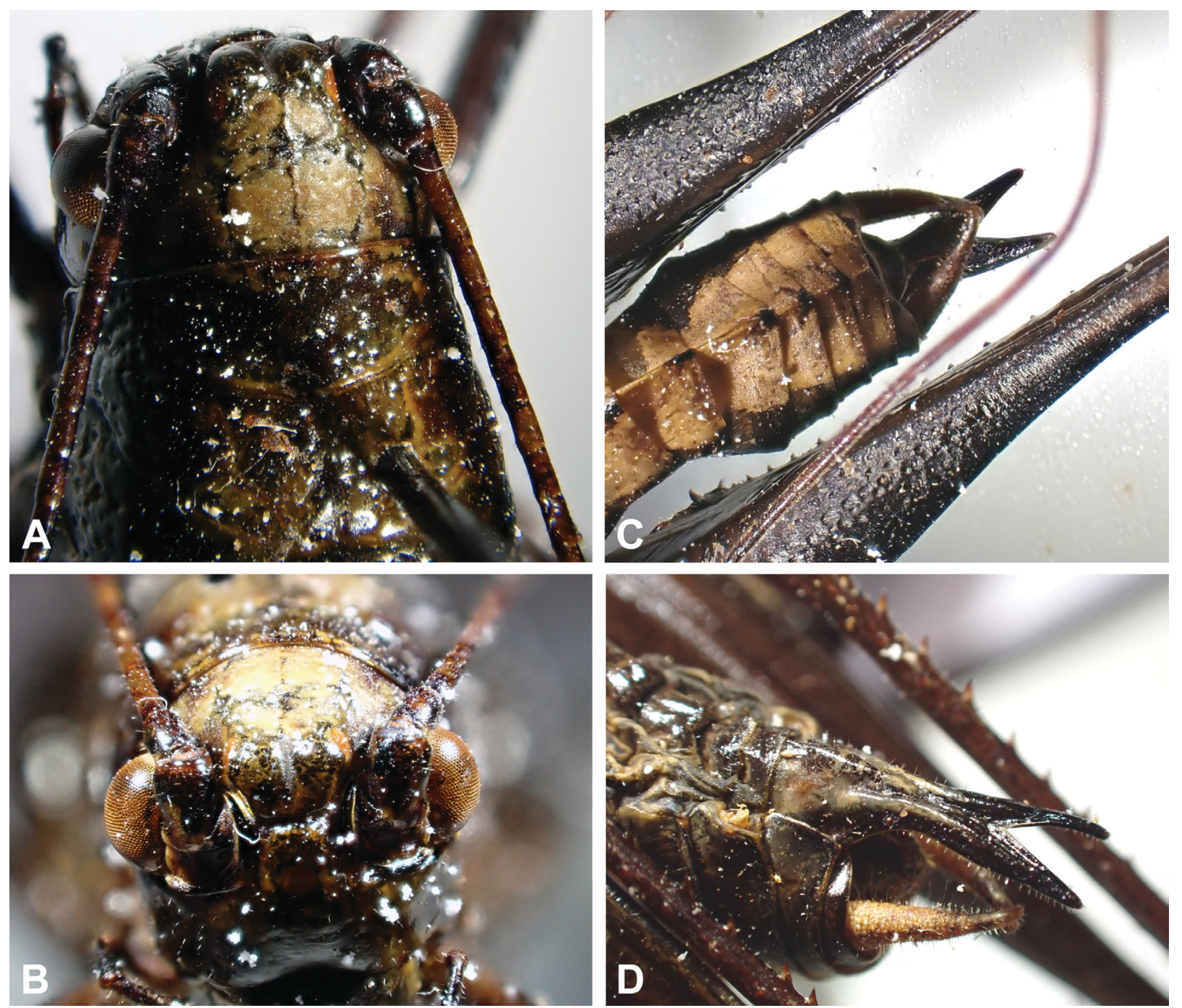

FIGURE 2. Morphological details of male Apteroscirtus dundoensis n. sp. (MNCN_Ent 305877) A. Dorsal view on head with fastigium verticis forming two bulges B. Frontal view on head with fastigium verticis $\mathbf{C}$. Dorsal view on abdominal apex with stout cerci and fork-shaped subgenital plate $\mathbf{D}$. Ventral view on subgenital plate. 
Description. Male. From its general body shape and colour a typical Apteroscirtus species: stout with long dark brown legs, body also dark brown with a dorsal light yellowish to hazel brown fascia on the abdomen and part of the head (Fig. 1 A, B). Head and antennae.- Antennae about twice the body length. Fastigium verticis with median indentation forming two small rounded bulges (Fig. 2 A, B). Fastigium verticis abruptly forming acute angle to face merging into frons of face without clear separation. Thorax.- Pronotum cylindrical with clearly discernible sulci dividing pro- and mesozona; disc of pronotum evenly rounded, mottled brown. Tegmina not discernible. Legs.-Legs long and slender, base of hind femur stout. Hind femora surpassing apex of body considerably, hind tibiae as long as femora. Tympana of fore tibiae oval and open on both sides. Abdomen.-Abdominal tergites smooth, medially with dark marking. Cerci stout, rounded and short (Fig. 2 C, D). Subgenital plate a typical fork, rather stout and short (Fig. 2 D); without styli.

Female. Larger than male but with the same colour pattern but comparatively shorter antennae (Fig. $1 \mathrm{C}, \mathrm{D}$ ). Bulges of fastigium verticis not as well-developed as in male but more smooth (Fig. 3 A, B). Pronotum broad with sulci clearly discernible on pro-, and mesozona; evenly rounded. No signs of tegmina, as male apterous. Legs as in male. Dorsum of abdomen as in male, medially with median dark markings. Ovipositor slender and slightly upcurved at posterior part (Fig. 3 D). Subgenital plate a broad shield (Fig. 3 C).
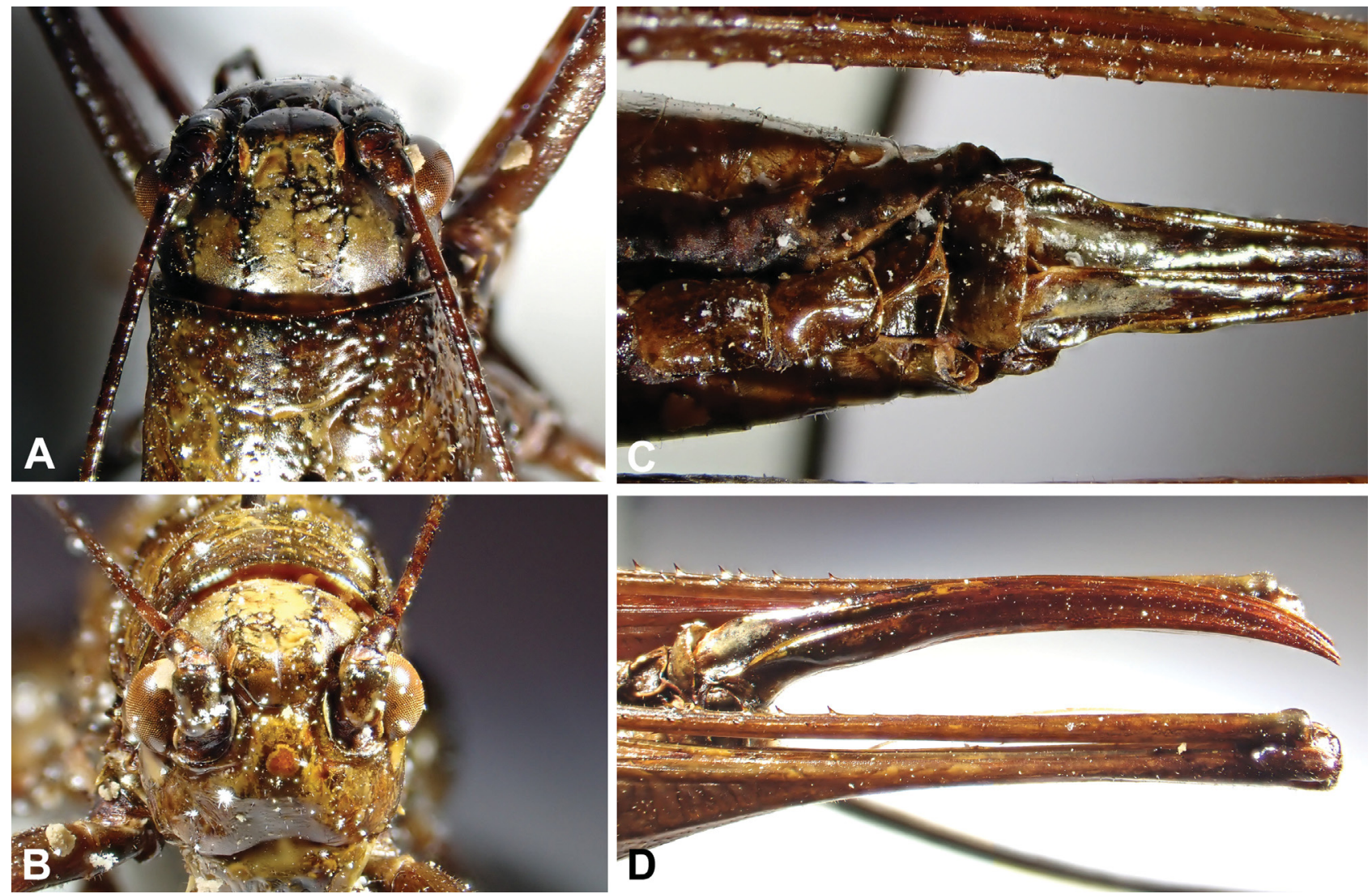

FIGURE 3. Morphological details of female Apteroscirtus dundoensis n. sp. (MNCN_Ent 305878). A. Dorsal view on head and fastigium verticis B. Frontal view on head with fastigium verticis C. Subgenital plate D. Lateral view on ovipositor.

Measurements. $(\mathbf{m m})$ Males ( $\mathrm{n}=1)$ : Body length: 23 (including subgenital plate); Median length of pronotum: 4.56; length of hind femur: 25 .

Measurements. $(\mathbf{m m})$ Females $(\mathrm{n}=2)$ : Body length: 27-29; Median length of pronotum: 5.2-5.4; length of hind femur 31.6-32.3; ovipositor: 20.3-21.2.

Diagnosis. In its general habitus similar to the stout A. densissimus Hemp, 2020 from the Nguru Mountains in Tanzania and thus different from the more fragile built A. planidorsatus Hemp, 2013 and the smaller but also stoutly built $A$. cristatus Hemp, 2013 from the West Usambara Mountains. A. densissimus, however, has clearly developed median ridges dorsal on the abdomen while in A. dundoensis n. sp. the dorsal abdomen is smooth (but with a dark patch medially on each tergite). A. inalatus (Karsch, 1886) differs from all other Apteroscirtus species in having tegmina. A. ruwenzoricus Rehn, 1914 is a small species with a very rounded body shape. Medially on the 


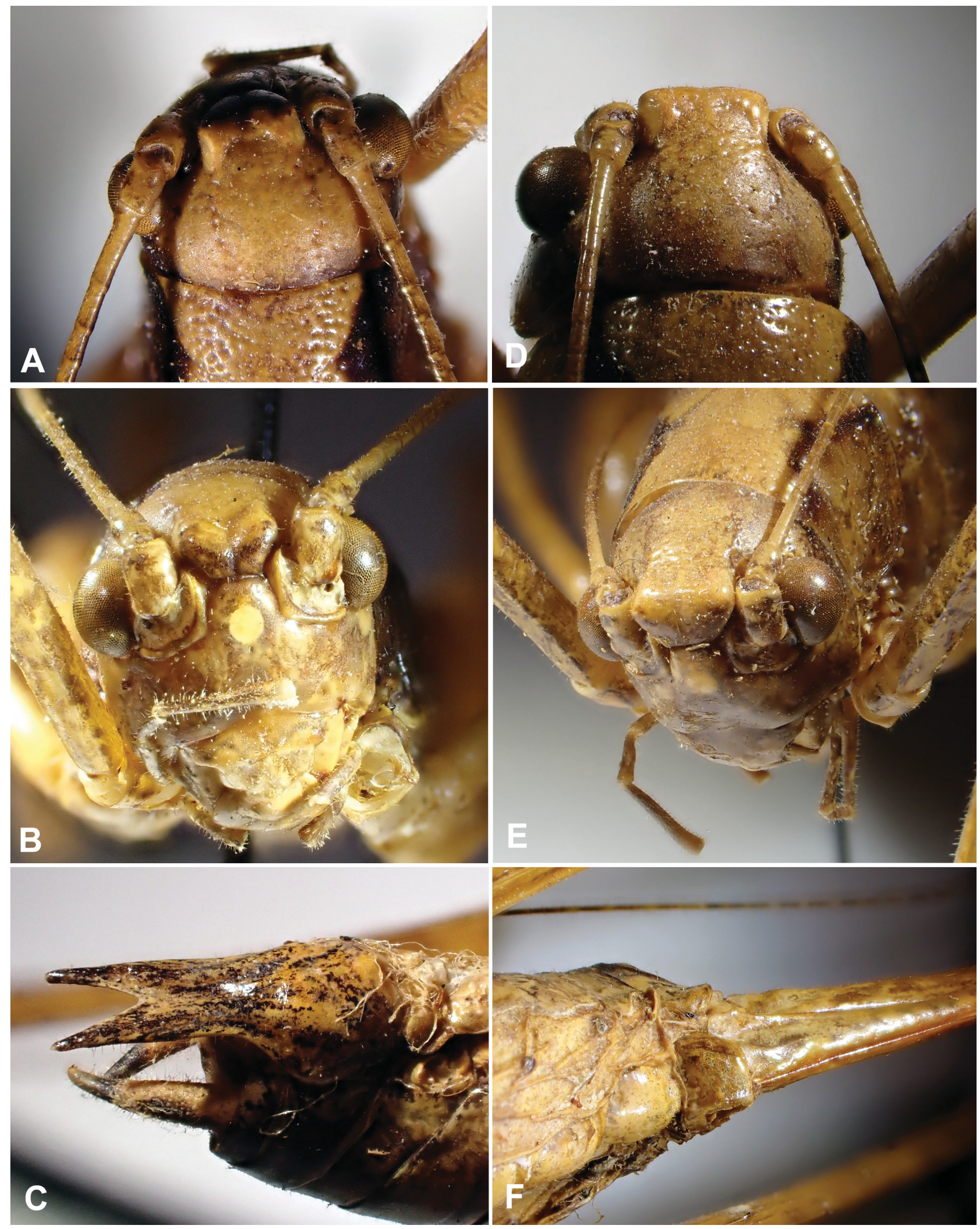

FIGURE 4. Morphological details of Apteroscirtus denudatus (Dibongo, Cameroon, MNCN) A, B. Dorsal and frontal view on male fastigium verticis (MNCN_Ent 305871) C. Subgenital plate (MNCN_Ent 305871) D, E. Dorsal and frontal view on female fastigium verticis (MNCN_Ent 305872) F. Female subgenital plate (MNCN_Ent 305872). 
tergites of the abdomen small ridges are typical while A. dundoensis n. sp. is larger and has no ridges medially on the tergites of the abdomen. Differentiated from the similar shaped and geographically adjacent occurring $A$. denudatus Karsch, 1891 by the fastigium verticis being more straight and edgy (forming two almost triangular structures when seen from the front, Fig. 4 A, B) in males of A. denudatus and small median knobs dorsally on the abdominal tergites (smooth in A. dundoensis n. sp.). The male subgenital plate in A. denudatus is short, hardly surpassing the cerci (Fig. 4 C), while it is longer and clearly surpassing the cerci in A. dundoensis n. sp. (Fig. 2 C, D). In females of A. denudatus the fastigium verticis has an almost straight margin (Fig. 4 D, E), hardly divided in the middle and a subgenital plate not as broad but longer than in A. dundoensis n. sp. (Fig. 4 F).

Etymology. Named after the city Dundo in northern Angola.

Distribution. Angola, Dundo.

\section{Discussion}

Except for A. inalatus described from the Democratic Republic of the Congo (Kuako to Kimpoko (Karsch 1886), Kimpoko being located near to Kinchasa and from Chinchoxo) having reduced tegmina, all other Apteroscirtus species have either tiny scale-like rests of tegmina or are apterous. Typical for the genus is an edgy fastigium verticis, often forming bulges or triangular structures. Very likely all Apteroscirtus species are dwellers of the forest ground being well-camouflaged in litter as known for the East African species (Hemp 2013; 2020). The record of an $A p$ teroscirtus species in Angola enlargens the area of occurrence for this genus to the south. Since lowland forest cover extends up to northern Angola also A. dundoensis n. sp. very likely has a similar habitat as other known Apteroscirtus species. Morphologically it is closely related to A. denudatus occurring further north. Since Apteroscirtus species are also found in Eastern Africa-today isolated in (sub-)montane forest along the Eastern Arc Mountains the genus must have spread before the once contiguous forest belt covering west to east Africa got fragmented by the increasing aridification of Africa (Covreur et al. 2008).

\section{Acknowledgements}

This research received support from the Synthesys Project http://www.synthesys.info/ which is financed by the European Community Research Infrastructure Action under the FP6 "Structuring the European Research Area Programme" enabling Claudia Hemp to visit the Museo Nacional de Ciencias Naturales, Madrid, Spain.

\section{References}

Couvreur, T.L., Chatrou, L.W., Sosef, M.S. \& Richardson, J.E. (2008) Molecular phylogenetics reveal multiple tertiary vicariance origins of the African rain forest trees. BMC Biology, 6, 54. https://doi.org/10.1186/1741-7007-6-54

Hemp, C. (2013) Annotated list of Tettigoniidae (Orthoptera) from the East Usambara Mountains, Tanzania and new Tettigoniidae species from East Africa. Zootaxa, 3737 (4), 301-350. https://doi.org/10.11646/zootaxa.3737.4.1

Hemp, C. (2020) New species of Mecopodinae (Orthoptera, Tettigoniidae) from Tanzania. Zootaxa, 4790 (1), $138-150$. https://doi.org/10.11646/zootaxa.4790.1.8

Karsch, F.A.F. (1886) Orthopterologische Beiträge I. Die Mekopodiden des Berliner zoologischen Museums. Berliner Entomologische Zeitschrift, 30, 107-118 pl. 4.

https://doi.org/10.1002/mmnd.47918860119 